\title{
Study on Space Environmental Design of Urban Rail Transit
}

\author{
Yan Chen and Yang Wang \\ Institute of Art \& Design, Nanchang Hangkong University, Nanchang, China
}

\begin{abstract}
In the wake of scientific progress and development of human society, urban rail transit system, as a high-efficient and energy-saving urban transit mode, has been increasingly favored and respected, due to its comprehensive advantages as convenience, security, comfort and environmental protection. This paper proceeds from the aspect of environmental art to analyze the current status of space environment of urban rail transit space and propose the design principles and methods for similar space.
\end{abstract}

\section{Keywords-urban rail transit; environmental art; space design}

\section{INTRODUCTION}

During the past years, railway transit, as the dominant transportation tool in urban areas, rail transit turns into an indispensable part in people's daily lives, along with the constantly upgrading comprehensive national strength and accelerated modernization progress in urban areas. The accelerated urban development has led to people's upgrading demands on urban environment quality and aesthetic consciousness; rail transit has been more and more concerned by the public for its comfort and visual aesthetics, as the carrier of urban transit pressure. Therefore, urban rail space environment is not only a carrier of transit space, but also a multi-functional urban space for art integration, history demonstration and cultural communication.

\section{CONCEPT \& CHARACTERS OF URBAN RAIL TRANSIT}

\section{A. Definition of Urban Rail Transit}

Urban transit acts as the important part of national economy. In the broad sense, urban rail transit indicates the rail rapid transit running on fixed rails within urban cities. There is no unified definition internationally for such a concept with a wide range. Generally speaking, urban rail transit in the broad sense indicates the rail transit system (different from road traffic) with medium passenger capacity or above in public urban passenger transportation system, featuring the rail transportation method as the major technical character. It mainly serves the public passenger transportation within urban areas, as a modern $3 \mathrm{D}$ transit system playing the key role in urban public passenger transit. According to the different technical features of rail transit system, it can be divided into metro, light rail and maglev train. In the world, metro system has broken though the wholly underground operation, turning into an underground-ground-elevated multi-plane rapid rail transit model integrating. Elevated metro is dominant for light rail, accompanied by ground rail and underground rail models. This paper conducts an analysis on the space environment of rail transit stations, including the internal space, external space and entrance and exit space of rail transit station buildings.

\section{B. Space Environment Characters of Urban Rail Transit 1) Publicity characters}

The close relationship between urban rail transit space and citizens' lives and transportation has decided the publicity of urban rail transit. And it is the place that provides daily service and social communication for most of urban citizens. Service the daily life of urban citizens, urban rail transit is of great significance to demonstration urban images and extend the lives of cities, as the important carrier of urban culture, ecology and aesthetics.

\section{2) Mobility characters}

As the space of public service, urban rail transit is closely related with citizens and their lives. The high mobility of rail transit space is determined by its transit quality. Transit space shall bring people flow together and then evacuate it. The gathering and evacuation have demonstrated its mobility. Therefore, we shall required public transit space to maintain sound connection with surrounded urban space, enjoy the unimpeded streamline relation, have the sufficient sidewalk width and multiple entrances and exists to satisfy with passengers' demands from different directions.

\section{StATUS ANALYSIS ON SPACE ENVIRONMENT OF URBAN RAIL TRANSIT}

Urban rail transit construction has been started since the early 1960th in China. Beijing Metro Line No. 1, as the first metro line in China, initiate its phase 1 project in 1965 and launched its pilot operation in October 1969, beginning the development history of urban rail transit in China.

Due to the huge difference of economic development levels between China and other countries in the world, urban rail transit appeared in China half of a century later than that in other countries in the world. And the internal design of space environment in rail system in other countries has become matured, with the integrity, richness and artistry exceeding those of China. The results of status investigation has shown that there are still various problems existing in the space environment of urban rail transit in China and many of shortcomings in terms of artistic environment design.

\section{A. Excessive Functional Simplification}

In the wake of the continuously social and economic development, urban citizens have higher and higher living 
demands; the simplified function of rail transit space, that has been far beyond satisfying the diversified demands of modern citizens, shall follow the diversified development tendency inevitably. At present, the rail transit spaces in most cities of China could only satisfy the transit function. Limited by geographical conditions and small space, the narrow space will be unfavorable for prospective development.

\section{B. Uncompleted Public Facility}

At present, the lack of public facilities in urban rail transit space is very common in China. The lack of construction of various infrastructures and barrier-free facilities has led to the universal lower of its overall quality and urban vigor, unable to satisfy modern citizens' material lives and spiritual demands and bring the sense of belonging and identity to citizens. Therefore, the public space design of rail stations shall put human-orientation priority, to provide citizens with the convenient, improved and public transit space from the perspective of users.

\section{Lack of Visual Aesthetics}

Urban rail transit space system is not only a transit space, but also a space for cultural transmission, history demonstration and artistic integration. The use of rail space system in China, still at the initiating stage, doesn't pay sufficient attention to the combination of art and urban rail space environment. Most of rail transit spaces, in lack of artistic design, feature the uniform decoration style, with toneless internal environment and non-innovative form designs in style and color without their own characteristics; the public art projects allocated in the spaces are mostly obsolete and unable to decorate and embellish the spaces. The sign system features poor identifiability without systematic and comprehensive color application. The unclear signs have made it difficult for passengers' rapid identification.

\section{Lack of Regional Culture}

Regional culture is the spiritual source of a nation and the mark of a city. To build the regional cultural brand for a city can promote to upgrade a city's popularity, enhance its core comprehensiveness and advance its economic development. Regional culture, as the element and theme in design, is related with environment art. However, the concept of constructing regional culture for rail transit space environment in China is relatively old-fashioned, without its own style or system. China hasn't found a path suitable for its concrete nation state, but blindly copying the design styles of rail space systems overseas, with the absence of its own regional cultural characters.

\section{DESIGN PRINCIPLE OF SPACE ENVIRONMENT OF URBAN RAIL TRANSIT}

The most fundamental structures of urban rail spatial system can be divided into three types, ground, underground and elevated stations. Facing with the rapid urban development at present, most of urban rails adopt underground stations, in order to save land and better utilize the underground space. Urban rail space is the important part of urban space and the spatial carrier that connecting city, environment and architectures, integrating transit, commercial and art functions.

The art design principles of urban rail transit space environment play the guiding role in the entire process of designing. According to the problems and current status of space environment summarized above, this paper proceeds from the aspects of function, security, culture and art to propose design principles and demands, to ensure that urban rail space environment to be "human-oriented" and to better serve the public.

\section{A. To Satisfy Demands of Diversified Functions}

In the wake of people's increasingly diversified social activities, single function of urban rail transit environment has been far beyond satisfying the diversified use demands modern citizens; and it becomes the evitable trend to build the urban rail transit environment with diversified functions. Rail transit space, with transit function as the basic prerequisite, shall satisfy the use demands of citizens on station transit space firstly. On the one hand, it shall ensure the transportation within the rail transit network and the convenient transfer with other means of transportation; organize passenger flow pulling in and out of stations orderly; take the effective connection between rail transit and surrounded transit facilities into consideration and process the relationship between transit faculties and passenger flow. On the other hand, the rail transit system shall make the planning layout of the internal and external space of stations based on people's behavioral habits with rational and clear functional division and dynamic layout, for passengers' rapid arrival at various functional areas to upgrade the transportation efficiency; set up supporting service facilities to satisfy passengers' various demands, e.g. setting up succinct and clear guiding signs for facilities including toilet, phone booth, newsstand, ticketing and supplementary ticketing booth, for passengers' rapid position and arrival; and to satisfy the basic transit functional demands of dense crowns of passengers, including the old, children and the disabled, to create the great space environment quality of rail transit.

\section{B. To Satisfy Demands of Security and Convenience Function}

Security, convenience and comfort are passengers' basic demands on public transit space. Those requirements, without qualitative indexes though, belong to immeasurable standards in urban design. However, in terms of the target of art design of rail space environment, those standards shall be the priority of design and the basic requirements to construct a secure and guaranteed public transit environment, because only when human safety is guaranteed, pursuits of higher level can be possible.

\section{To Satisfy Demands of Regional Cultural Characters}

In the concept of environment art design for urban rail space system, urban rail space is not only a simple communication tool traditionally, but also the place that integrates and demonstrates urban regional culture and humanistic spirit. Rail transit stations are needed to act as the carriers to display urban regional cultures and images. Cities of different natures will form their own regional cultural features, including different historic background, cultural significance 
and unique life concepts, behavior habits and aesthetic ideas of local residents. Rail transit space environment shall focus on the resources and image characters and demonstrate the spiritual features and regional cultural atmosphere of the cities. On the one hand, the art design of space environment in rail stations shall be coordinated with surrounded urban environment to maintain the uniformity and integrity of regional spatial forms and local features; on the other hand, the art design shall demonstrate regional cultures in public spatial environment of stations in the form of art, to create the highquality public space with cultural deposit and artistic taste. Such a design concept integrating regional features can be positive in promoting urban images and charms and extend regional urban cultures.

\section{To Satisfy Demands of Artistic Aesthetics}

The environment art design of urban rail space system shall not only have realistic functions, but also the value of aesthetics. In the art design of urban rail space, the art demonstration shall take the features of rail spatial form, scale, people's psychology, concept, ideology and the application of material technology into priority consideration; secondly, according to the beautiful rule of form and principles of environment psychology by means of visual expression, including comparison and uniform, equilibrium and symmetry and rhythm and cadence, art design shall make the change processing of spatial form, color and material on the one hand, and coordinate and uniform with the surrounded architectures and environment on the other hand, in order to create a public environment with rich spatial form to demonstrate the aesthetic and comfortable sense.

\section{CONCLUSION}

In conclusion, the environment of urban rail transit is characterized by publicity and high mobility. The art environment design shall proceed from satisfying the use function; take the aesthetic demands and habits of local residents into consideration; master the overall styles, features and regional cultures; integrate surrounded architectures and historical environments together, to ensure the coordination and uniform between rail stations and surrounded landscapes, in order to create a public rail space environment integrating speediness, security, comfort and aesthetics.

\section{REFERENCE}

[1] Mao Baohua. Planning and Designing of Urban Rail Transit [M]. Beijing: China Communications Press, 2006.

[2] Wang Zhong. Introduction to Public Art of Underground Transit Space [M]. Beijing: Beijing University Press, 2007.

[3] Li Jiansheng. Public Art and Urban Culture [M]. Beijing: Beijing University Press. 2012.

[4] Liu Jieyi. Urban Dimensional Development and Rail Transit [M]. Nanjing: Southeast University Press, 2012. 